\title{
Clinicians as advocates amid refugee resettlement agency closures
}

\author{
Hafifa Siddiq ${ }^{1}$ (D) Julia Rosenberg ${ }^{2}$
}

Accepted: 7 July 2021 / Published online: 21 July 2021

(c) The Author(s) 2021

\begin{abstract}
As ongoing war and violence forcibly displace people worldwide, resettlement remains a critical response to the unprecedented global refugee crisis. In recent years, however, the USA (US) has diminished admissions, forcing agencies to shutter offices and resettlement programs across the nation-posing a silent threat to the refugee resettlement system. We provide historical context of refugee resettlement, discuss challenges, and offer recommendations for healthcare providers to become more effective advocates for refugee health in the USA. The need is urgent for healthcare providers and institutions - particularly in regions of high resettlementto advocate for expanding and assuring sustainable capacity to care for refugees. Key elements include promotion of trauma-informed care, integration of social services in primary care settings, partnership with community-based organizations to promote continuation of care, advocacy for resources and services, and opposition to policies detrimental to the health of refugees and immigrants.
\end{abstract}

Keywords Refugees $\cdot$ Clinician advocate $\cdot$ Resettlement agency $\cdot$ Health policy . Health services · Healthcare disparities

Hafifa Siddiq

hafifasiddiq@ucla.edu

Julia Rosenberg

julia.rosenberg@yale.edu

1 National Clinician Scholars Program, Division of General Internal Medicine and Health Services Research, University of California, Los Angeles, 1100 Glendon Ave. Suite 900, Los Angeles, CA 90024, USA

2 Yale University School of Medicine, Yale University, New Haven, CT, USA 


\section{Key messages}

1. As the refugee crisis reaches unprecedented magnitude, the USA drastically diminished refugee admissions in recent years-threatening the national refugee resettlement system.

2. Healthcare providers can play a critical role in advocating for refugees by providing trauma-informed care, integrating social services within primary care, developing community partnerships to address social service needs, and promoting continuity of care.

3. Healthcare providers should address structural and social determinants of refugees' health, advocate improved policies for refugees, and recognize the repercussions of anti-immigration policies on refugees' health and wellbeing.

\section{Introduction}

Amid a global refugee crisis, the entire United States (US) refugee resettlement system is in peril [1]. As of mid-2020, the number of displaced people worldwide had reached an unprecedented 80 million and the numbers of those displaced is projected to continue to increase [1]. Among the world's displaced populations, 26.3 million are refugees [1]. Recent anti-immigrant policies during the Trump Administration and the drastic reduction of refugee admissions in the USA may have farreaching adverse consequences for the health of refugees and the sustainability of the US resettlement program [2]. Resettlement agencies provide critical resettlement services including housing placement and employment assistance for newly resettled refugees in the USA and help refugees start their lives. As a result of diminishing admittance of refugees into the USA since 2017, resettlement agencies have shuttered more than 100 out of an estimated 325 programs and offices across the nation [3, 4]. Systematic decimation of this infrastructure threatens critical refugee health screening and social services programs, leaving refugees and their surrounding communities to deal with the consequences. To again serve the numbers of refugees as it has for decades, the USA must rebuild the infrastructure and human power of the refugee resettlement system. Healthcare providers should play critical roles, addressing health care needs and advocating for resettled refugee communities-and can become a stronger force.

In this Viewpoint, we provide an overview of the now crumbling US refugee resettlement system - crumbling as a result of policies introduced by the Administration of President Trump (2017-2021) [2]. Temporary suspension of refugee resettlement during the COVID-19 pandemic exacerbated deterioration in capacity of the US system [5]. We set the US system in context internationally, then highlight the role of US resettlement agencies to address newly resettled refugees' social service and health care needs. Resettlement agencies face solvency challenges in a politicized climate that has denigrated refugees. Healthcare 
providers in outpatient and primary care settings can address an urgent need to advocate for sustainable capacity to care for refugees, particularly in regions of high resettlement. Providers can also promote trauma-informed care, integration of social services in primary care settings, partnership with community-based organizations to foster continuity of care, advocacy for resources and services, and opposition to policies detrimental to the health of refugees and immigrants. Because many aspects of the US refugee resettlement system remain in flux, the policies and systems described below may continue to evolve. See Table 1 for common terms and definitions.

\section{Context for US refugee resettlement: United Nations and refugees around the world}

After the atrocities of World War II, the international community held the 1951 Refugee Convention in Geneva to adopt protocols and outline a framework for legal protections and social rights for protecting refugees [6]. At that time, the United Nations (UN) established the UN Health Commissioner for Refugees (UNHCR) a global agency mandated to aid and protect refugees, to assist in voluntary repatriation, and local integration, or facilitate resettlement to a third country, or both. According to the 1951 Refugee Convention, a refugee is defined as a "person who is outside his or her country of nationality or habitual residence; has a well-founded fear of being persecuted because of his or her race, religion, nationality, membership of a particular social group or political opinion; and is unable or unwilling to avail him- or herself of the protection of that country, or to return there, for fear of persecution" [6]. Refugees are forced to flee due to a threat of persecution and lack protection of their own country. An immigrant, in comparison, may leave his or her country for other reasons like employment, family reunification, or study, and may do so under the protection of their country of origin [6]. (See Table 1 for definitions of US immigration categories.)

Resettlement is a vital response to an ongoing global refugee crisis. Resettlement offers a pathway to safety, freedom, and independence and a humane alternative to refugee camps [2]. According to the UNHCR, there are over 20 million refugees worldwide but only less than one percent of them are resettled each year [7]. Globally, countries resettled 92,000 refugees in 2018, down from 103,000 in 2017 and a peak of 189,000 in 2016 [8,9]. The USA has historically resettled more refugees annually than all the other resettlement countries in the world combined. After the USA that resettled 33,000 refugees in 2017, Canada resettled 27,000 refugees and Australia resettled 15,000 refugees. In 2017, Canada led other resettlement countries in resettlement per capita by resettling 725 refugees per 1 million residents, followed by Australia (618), and Norway (528). By contrast, the USA resettled only 102 refugees per 1 million residents in 2019 [9]. As resettlement in the USA dramatically decreased refugee admissions in recent years, the rest of the world followed suit. In 2018, only 25 countries committed to resettling refugees, down from 37 in 2016 [10]. This decrease in numbers of people resettled across the world and the decrease in countries' commitment to refugee resettlement is occurring when the number of 
Table 1 Terms and Definitions

US immigration categories

Asylee

Asylum seeker

Displaced population

Internally displaced people (IDP)

Immigrant

Lawful permanent resident

Refugee

Organizations and roles

Case manager or social worker

Ethnic-community-based organization

Health navigator

Office of Refugee Resettlement

Refugee resettlement program

Refugee resettlement system
A person fleeing persecution or serious danger, and granted, by a State, protection on its territory

A person fleeing persecution or serious danger and seeking international protection

People who involuntarily leave their homes as a result of a natural, technological or deliberate event. Displaced populations include refugees, asylum seekers and internally displaced people

People who are displaced within their own countries and remain under the protection of government, even if that government is the reason for their displacement

An individual who voluntarily leaves their country of origin and enters another country to reside permanently

Lawful permanent residents (LPRs), also known as "green card" holders, are non-citizens who are lawfully authorized to live permanently within the U.S

The 1951 Refugee Convention is a key legal document and defines a refugee as: "someone who is unable or unwilling to return to their country of origin owing to a well-founded fear of being persecuted for reasons of race, religion, nationality, membership of a particular social group, or political opinion."

A staff person at a resettlement agency assigned to assist a refugee in navigating social service programs. In general, the role of the case manager is to undertake assessment, monitoring, planning, advocacy and linking people with rehabilitation and support services

A community-based organization, comprised primarily of refugees, for the specific purpose of providing assistance to other refugees

An individual or organization trained and able to help consumers, small businesses and their employees as they look for health coverage options through the 'Marketplace', including completing eligibility and enrollment forms

A program within the US Department of Health and Human Services that provides resources for refugees, asylum seekers, and other new arrivals to the US to assist with their integration into their new community

A program responsible for coordinating and funding some refugee-specific services and benefits, including RMA

A public-private partnership that assists in the permanent resettlement of refugees 
Table 1 (continued)

Resettlement agency

United Nations High Commissioner for Refugees

United Nations Relief and Works Agency

United States (US) Citizenship and Immigration Services

US Immigration and Customs Enforcement

US services and programs

Medicaid

Children's Health Insurance Program (CHIP)

Refugee Medical Assistance (RMA)

Refugee resettlement

Social service programs

Supplemental Nutrition Assistance Program (SNAP)

Women, Infant, \& Children (WIC)
A non-profit organization that has a cooperative agreement with the federal government to assist refugees in resettling in the United States

A global agency mandated to aid and protect refugees, to assist in their voluntary repatriation, local integration, or resettlement to a third country

A global agency, established by the United Nations General Assembly of 1949, to carry out direct relief. works programs specifically for Palestine refugees

An agency of the United States Department of Homeland Security that administers the country's naturalization and immigration system

A federal law enforcement agency under the US Department of Homeland Security that enforces immigration and customs laws

A federal health care program run by the state that assists low-income families or individuals in paying for doctor visits, hospital stays, and long-term medical care

A federal health care program for that provides lowcost health insurance to children in families that earn too much money to qualify for Medicaid

A temporary medical benefit funded by the federal government available to refugees and other eligible beneficiaries

The transfer of refugees from the country in which they have sought asylum to another that has agreed to admit them. The refugees will usually be granted asylum or some other form of long-term resident rights and, in many cases, will have the opportunity to become naturalized citizens

Programs administered by the federal, state, or local government using government funding directed at reducing poverty, improving opportunities for low-income adults or children, promoting selfsufficiency, rehabilitation, and include services like Medicaid, SNAP, and WIC

A federal program that provides food-purchasing assistance for low- and no-income people

A federal program that provides breastfeeding support, nutritious foods, information on healthy eating, and referrals to health care to pregnant, postpartum and breastfeeding women and children up to age five

refugees is increasing each year. Projected worsening of conflicts in fragile states and concurrent climate change will only add to the dramatic rise in displaced populations, increasing the severity and urgency of the refugee crisis $[11,12]$. 


\section{The US refugee resettlement system}

The US refugee resettlement system, a public-private partnership that assists in the permanent resettlement of refugees within the US, is the most extensive in the world - a distinction held by the country since the passage of the Refugee Act of 1980. This Act solidified the relationship between the public (made up of governmental agencies) and private organizations (nongovernmental organizations). It established a national refugee resettlement program (comprised of services provided by resettlement agencies and refugee-serving organizations) to help refugees integrate and achieve self-sufficiency in the US [13]. The Act, established after the atrocities of World War II and passed with bipartisan support, aligns with the United Nation's 1948 Universal Declaration of Human Rights that guarantees the right of refugees to seek protection in other countries [13].

Since the passage of the Act, the USA has resettled more than 3 million refugees [1]. Each year, the US President initiates the resettlement process by setting an annual limit for the number of refugees the USA will accept. Refugees undergo intensive screening that involves multiple federal departments and overseas processing of each applicant by the US Citizenship and Immigration Services [14]. Former President Trump set an historic low number of refugees to be admitted each year he was in office, setting the refugee ceiling at 18,000 in 2020 and 15,000 refugees in 2021 - a more than sevenfold reduction from 110,000 refugees allowed in 2017 [15]. In addition, from March through June 2020, the UNHCR suspended resettlement travel for refugees because of the COVID-19 pandemic [16]. Despite promising to reverse Trump era limits on refugee admissions, President Biden upheld the refugee admission cap of 15,000, a number set by former President Trump, sparking resistance from human rights groups [17]. As a result, President Biden announced in 2021 the revision of the US annual admissions to cap to 62,500 and stated "This erases historically low number set by the previous administration of 15,000 , which did not reflect America's values as a nation that welcomes and supports refugees" [17].

The US refugee resettlement systems involve coordination of services between federal agencies, nongovernmental organizations (NGOs), and local services organizations [18]. The US Refugee Act of 1980 established the Office of Refugee Resettlement (ORR), responsible for providing resources for refugees, asylum seekers, and other new arrivals to the USA to assist them with integration to become selfsufficient [2]. The ORR allocates funds based on the number of refugees resettled in each state; funding is dependent on the arrival of refugees [19]. When refugees arrive in the USA, their sponsoring refugee agency receives a Reception and Placement grant of $\$ 2,175$ per refugee to pay for certain expenses, including food, rent, and job placement services during the initial 90 days of resettlement $[4,18,19]$. Other funding sources include longer-term state grants or private donations to help refugees beyond the initial 90 day resettlement period. Case managers who work with refugee clients typically prepare, rent, and furnish an apartment for an incoming refugee family. Most often, the case manager uses these funds before the refugee arrives in the USA. 


\section{Refugee health care provisions}

The US Department of Health and Human Services requires refugees to undergo mandatory medical exams pre-departure and upon arrival in the USA. Medical facilities provide primary health care services in the USA, not refugee agencies. Upon arrival, refugees become eligible for Refugee Medical Assistance (RMA), a form of short-term health insurance, for up to eight months. After this period, refugees must obtain public or private health care insurance to pay for care [20, 21]. The RMA covers similar medical expenses as Medicaid (a federal and state program that helps with healthcare costs for people with limited income and resources) and includes coverage for a required domestic medical examination within 90 days of arrival in the USA. Some refugees may be eligible for government health insurance such as Medicaid for their first 7 years in the country [20].

Gaps in health insurance coverage remain for refugees and other immigrants in the USA. Based on an analysis of 2018 American Community Survey data, noncitizens are substantially more likely to be uninsured compared to US citizens [22]. Among non-citizens, about $23 \%$ of lawfully present immigrants (including refugees, asylees, and other lawful permanent residents) lack health insurance to pay for medical services [22]. These gaps in coverage demonstrate a need for policymakers to consider promoting the continuation of health insurance to cover health services especially when RMA coverage lapses after eight months.

\section{Refugee health and barriers to health care}

Refugees experience a triple burden of ill health: non-communicable diseases, infectious diseases, and mental health disorders [23]. Before resettlement, refugees may experience violence, trauma, and exposure to endemic communicable diseases. After resettlement, these exposures and their effects add to the stresses of integrating into a new society and increase the risk for developing chronic health problems endemic to high-income countries of resettlement [24-26]. Robust population-level surveys among refugees are scarce, and reports of the prevalence of mental health disorders vary widely, from 20 to 80 percent among refugees [27]. These may include anxiety, post-traumatic stress disorder (PTSD), depression, and somatization. According to the American Psychiatric Association, approximately 1 in 3 refugees and asylum seekers appear to suffer from at least one of these mental health conditions [28]. Refugees are at particular risk for mental health challenges because civilians in war zones typically experience at least one traumatic event due to war, and war refugees often are subjected to torture, sexual violence, and other traumatic events [29].

Healthcare providers play a critical role in promoting resilience and mitigating adverse effects of trauma for immigrant and refugee families through 'traumainformed care'. Trauma-informed care refers to the context in which trauma is addressed among people receiving services and how caregivers incorporate 
fundamental trauma principles in organizational culture. Principles of traumainformed care include promoting safety, building trusting relationships, providing peer support, collaborating with patients and families, promoting a sense of control and empowerment, and acknowledging cultural, historical and gender issues [30]. The American Academy of Pediatrics recommends that caregivers use a trauma-informed care approach with immigrant and refugee families [31].

Post-migration stressors such as economic hardship and social and cultural challenges of adjustment to the USA compound the burden on refugees already experiencing trauma and other risk factors for mental illness [30, 32]. Despite being more likely to work than their US-born counterparts, refugees are also more likely to have lower income than the rest of the general population [33]. Evidence shows how poor socioeconomic status and disadvantaged living conditions are associated with worse mental health [32]. In addition, criminalization of immigrants and experiences like discrimination and racism and sentiment against immigrants generally harm health and mental health [34, 35].

Although refugees are eligible for health insurance in the USA, they underutilize services, including mental health care, dental care, and preventive health services including vaccination and cancer screening services, compared with their US-born counterparts [36, 37]. Refugees and those who provide health and social services to refugees report that a significant barrier to the use of health services is limited English language proficiency and lack of knowledge about health resources and available services [30]. Other barriers include lack of provision of health service information upon arrival in the USA, limited understanding of the complex healthcare and specialty services in the USA, and logistical issues related to lack of transportation or availability of interpreters [30]. Stigma toward mental health and unfamiliarity with preventive health care may also further inhibit refugees' use of services [34].

\section{Role of refugee resettlement agencies}

Refugee resettlement agencies promote integration of refugees and help them to set up their lives in the USA. These agencies provide resettlement services including housing placement and employment assistance to promote self-sufficiency as soon as possible. The agencies also provide newly resettled refugees with vital resources for social services, and especially important, interpretation services [38]. Because the USA admits refugees from over 150 countries, culturally and specific languageand dialect-tailored services are critical-and even more so as refugee populations are increasing in diversity.

To mitigate unfamiliarity with the complex array of social and health services and overcome barriers to care, refugee resettlement agencies provide case management, coordinating services for people with complex needs, and collaborate with health services [39]. Resettlement agencies may be staffed by case managers, social workers, health navigators, or other support staff with roles that may overlap with one another when working with refugee clients. For example, case managers may conduct social needs screening for refugees and other clients related to social support, food insecurity, social isolation, housing safety, homelessness, transportation 
barriers, job placement, and financial insecurity. They also assist refugees to sign up for social service programs, and may provide peer support in the home. So called 'health navigators' may conduct health-related screening, provide nutrition and physical health literacy, assist in enrolling in health care coverage, schedule required medical exams, and secure transportation or language interpreters when available.

Agency staff can promote communication between designated refugee clinic staff and the resettlement agency and frequently work closely with nearby healthcare providers, using their familiarity with supplemental resources and services-such as nutrition and health services listed in Table 1 [38]. Answering the call to integrate social care into health care delivery - a call championed by organizations like the National Academies of Sciences, Engineering, and Medicine-may help bring together resources within the primary care setting to support refugee patients [38].

Refugee resettlement agencies may also connect refugees with local ethnic community-based organizations (E-CBOs) or other community networks including faithbased organizations or social groups that serve key roles in the integration of refugees within communities. E-CBOs are community-based organizations comprised primarily of refugees that assist other refugees. Services offered through E-CBOs may overlap with resettlement agencies and provide counseling, medical care, youth development, employment counseling, social adjustment services, cultural preservation and information, and referral services while continuing to address the unique cultural needs of that community. They often have culturally and linguistically competent staff to help connect knowledgeable community members with recently arrived refugees. When refugees no longer receive resettlement agency services during their initial resettlement period, E-CBOs attempt to fill refugees' needs for longer-term support and services for the community without regard to duration of stay in the USA $[18,38]$.

\section{Socio-political climate and challenges for refugee resettlement agencies}

Policies and executive orders by the Trump administration may have negatively impacted the overall health and wellbeing of refugee populations in the USA [40]. The anti-immigrant Trump era socio-political climate contributed to anti-immigrant policies, including the lowered cap of refugee admissions, detention of a large proportion of asylum seekers in US Immigration and Customs Enforcement (ICE) facilities, tightened restrictions on immigration and travel bans, and further restricted public charge rules (described below) [40-44].

The reduction in refugee admissions, coupled with suspensions of refugee resettlement programs related to the COVID-19 pandemic, threatens the future of refugee resettlement in the USA [4]. Inconsistent numbers of refugees admitted undermine federal funding. In turn, the funding cuts threaten US protection of refugees because refugee resettlement agencies rely on federal funding allocated per refugee sponsored. Dwindling admissions have driven staff layoffs and office closures [18]. Over 100 of 325 agency offices and organizations, including some that had been providing essential services to the community for half a century, 
have reportedly closed their doors, and many more may be in precarious situations amid the COVID-19 pandemic [4]. In addition, an executive order in 2017 banned arrival or re-entry of refugees and other migrants from Muslim-majority countries of Syria, Iraq, Somalia, Yemen, Iran, Sudan, and Libya, an order then reversed by current President Biden [42]. The American Civil Liberties Union documented the devastating impact on US families through family separations and uprooting of lives, not only at the border, but also overseas where the US government barred family reunification [45]. The dominant populations in countries included in this ban were made up of individuals of color (non-white). These countries also have substantial Muslim populations.

The former Trump Administration attempted to reduce the number of people eligible for permanent residency with tightening of 'public charge rules' [43]. These rules permit government to deny immigrants visas or entry into the US due to disabilities or lack of economic resources. Such policy changes create a chilling effect to decrease enrollment in federal benefit programs, even for immigrants who have legal entitlement to the benefits [44]. The programs offer social and health services include: Supplemental Nutritional Assistance Program (SNAP), Women, Infants and Children (WIC), Medicaid for children, and publicly subsidized housing. SNAP and WIC provide food-purchasing assistance for low- and no-income people. Confusion about which rules apply to whom and about use of which programs may adversely affect immigration status-often leaves eligible refugees uncertain about what services they may use legally. Researchers estimated in 2019 that one in seven adults in immigrant families avoided social service programs due to concerns about public charge rules [43]. Thus, thousands of eligible, low-income children do not benefit from legally available government support, even during the severe COVID-19 health and economic crisis [44].

\section{Recommendations for healthcare providers to support refugees}

The burdens to refugees' wellbeing that we enumerate above amount to 'structural determinants' of ill health [46, 47]. Healthcare providers should be aware of root causes of health inequities experienced by refugees and advocate for improvements in the US refugee resettlement program. These root causes are 'structural' and include economic, social, and political mechanisms that cause health and social inequalities [46]. Providers can advocate against discriminatory policies targeting immigrants and refugees and recognize the consequences to health of structural barriers, such as poverty and racism. These barriers inhibit attaining a living wage through decent jobs, quality education, and secure housing and safe communities. In addition to supporting changes in national policy under the Biden Administration (starting in 2021) to reverse the problems caused by the Trump administration, we offer recommendations for how healthcare providers can contribute to meeting the comprehensive health and social needs of refugees by leveraging existing community-based resources. 


\section{Recommendations}

1. Promote trauma-informed care. Healthcare providers can promote resilience and mitigate negative impacts of pre-migration trauma among refugee youth and families with trauma-informed care [30, 48, 49]. Healthcare providers can make clinical encounters therapeutic while minimizing re-traumatization, if they:

- Establish a relationship with the patient prior to referring clients to local and trusted resources and ask permission before discussing traumatic events or performing invasive procedures.

- Inform patients that they may request a providers or interpreters or both by certain attributes, such as gender. Many refugees are not aware of this right.

- Assure that screening and follow-up for mental and physical health issues are sensitive to patients' cultural beliefs and values even when these do not align with Western biomedical models of treatment.

- Promote a safe space for immigrants and refugees in healthcare settings and involve administrators, supervisors, and other ancillary staff who will be crucial for successful adoption and implementation of trauma-informed care.

2. Integrate social and mental health services into primary care. Healthcare providers can work with their practice teams and use community resources to integrate social and mental health services within the healthcare setting with the following [50-53]:

- Ensure that integrated care service providers have and use support services to learn about specfic cultural needs of newly resettled refugees.

- Screen for and address social service needs routinely.

- Provide language interpreters to improve quality and availability of care, to ensure clear communication and to help providers learn refugees' cultural conceptions of health and treatment and refugees' ways of expressing mental health symptoms.

- Engage community resources and clinic support staff to address unmet social service needs and limitations in primary care during the COVID-19 pandemic.

- Use 'tele-health' to expand social and mental health services for patients with limited transportation or other barriers, and ensure interpretation for all virtual services.

- Educate and inform refugee patients about confidentiality of in person and tele-health visits.

3. Promote Partnerships with Community-Based Organizations. Healthcare providers can work with the local community to address the complex needs of refugees in the following ways [43]:

- Identify refugee resettlement trends and culturally specific and culturally sensitive community resources in the local region.

- Include case managers and health navigators to promote continuity of care and ensure timely health screenings and follow-up. 
- Refer patients to local culturally tailored community mental health services when needed.

- Promote collaboration and clear communication between healthcare providers and community organizations to improve responses to one another's needs through timely and coordinated efforts.

- Foster a partnership between clinics with refugee resettlement agencies and other NGOs working with immigrant and refugee communities, including those that provide trauma-informed social and legal services.

- Strengthen community-academic partnerships by seeking opportunities to share resources and funding.

4. Educate and advocate for support and funding for services to support refugees. Healthcare providers should recognize detrimental effects of anti-immigration policies and advocate for refugees' health and wellbeing by [54]:

- Educate nurse, physician and other healthcare professionals-in-training about immigrant health, including the structural barriers and social determinants of health.

- Encourage these trainees to use social media and other means to contact local representatives of the city or state, to express their views on policies and amplify the effects of advocacy.

- Combine health professionals' voices with individual and organizational-level initiatives to advocate for legislative support and funding to improve health of immigrants and refugees through.

\section{Familiarize Oneself with and Harness Key Resources and Tools for Provid-} ers.

- Use an online tool for service providers that allows each provider to help their clients understand if use of public health benefits may interfere with clients' options for gaining their desired immigration status [55].

- Educate trainees to make use of tools (such as the US Centers for Disease Control and Prevention (CDC) and EthnoMed), that provide refugee health profiles for major refugee groups in the USA [56, 57].

- Engage with refugee support networks and become involved with advocacy, research, and practice groups, including the Society of Refugee Healthcare Providers and the American Public Health Association Caucus of Immigrant and Refugee Health to make use of these tools [58].

- Use an online toolkit to implement changes in policy and action that promote the physical and psychological safety of immigrant patients in hospital and clinic settings [59].

\section{Conclusion}

The atrophy of the US resettlement system has far-reaching sequelae for the present and future of the US refugee resettlement program and its intended beneficiaries. Trump era policy changes stoked anti-immigrant sentiment and destabilized the 
resettlement agency system. The need to promote a sustainable refugee resettlement system in the USA is urgent. Health professionals can increase capacity and improve care for immigrant and refugee families by using trauma-informed care, integrating social and mental health services in primary care settings, partnering with refugee resettlement agencies to promote continuation of care, and advocating for policies and legislation to fund these initiatives.

Acknowledgements Dr. Siddiq acknowledges funding support through the National Clinician Scholars Program (NCSP) and from the UCLA/Charles R. Drew University Resource Center for Minority Aging Research Center for Health Improvement of Minority Elderly under Award Number P30-AG021684 (Magione \& Duru, Co-PI). The article contains solely the opinions of the authors and do not represent the official views of NCSP or its partners, including the US Department of Veterans Affairs and the United States Government, or the National Institutes of Health.

\section{Declarations}

Conflict of interest On behalf of all authors, the corresponding author states that there is no conflict of interest.

Open Access This article is licensed under a Creative Commons Attribution 4.0 International License, which permits use, sharing, adaptation, distribution and reproduction in any medium or format, as long as you give appropriate credit to the original author(s) and the source, provide a link to the Creative Commons licence, and indicate if changes were made. The images or other third party material in this article are included in the article's Creative Commons licence, unless indicated otherwise in a credit line to the material. If material is not included in the article's Creative Commons licence and your intended use is not permitted by statutory regulation or exceeds the permitted use, you will need to obtain permission directly from the copyright holder. To view a copy of this licence, visit http://creativecommons.org/licen ses/by/4.0/.

\section{References}

1. United Nations Health Commissioner of Refugees (UNCHR). Refugee data finder. 2021. https:// www.unhcr.org/refugee-statistics/. Accessed 10 May 2021.

2. Welch K. Research Brief: A Pivotal Moment for the U.S. Refugee Resettlement Program. 2021. Haas Institute. https://belonging.berkeley.edu/sites/default/files/haasinstitute_usrefugeeresettlment_ june2017_publish.pdf. Accessed 10 Jan 2021.

3. Migration Policy Institute. Despite Trump Invitation to Stop Taking Refugees, Red and Blue States Alike Endorse Resettlement. 2020. https://www.migrationpolicy.org/article/despite-trump-invit ation-stop-taking-refugees-red-and-blue-states-alike-endorse-resettlement. Accessed 10 Jan 2021.

4. Karas T. US refugee agencies wither as Trump administration cuts numbers to historic lows. The World. 2019. https://www.pri.org/stories/2019-09-27/us-refugee-agencies-wither-trump-administra tion-cuts-numbers-historic-lows. Accessed 10 Jan 2021.

5. Grant A. Coronavirus, refugees, and government policy: the state of U.S. Refugee Resettlement during the coronavirus pandemic. World Med Health Policy. 2020. https://doi.org/10.1002/wmh3.362.

6. UNHCR. The 1951 Convention Relating to the Status of Refugees and its 1967 Protocol. 2011. https://www.unhcr.org/en-us/about-us/background/4ec262df9/1951-convention-relating-status-refug ees-its-1967-protocol.html. Accessed 10 Jan 2021.

7. UNHCR. Resettlement. 2021. https://www.unhcr.org/en-us/resettlement.html. Accessed 15 May 2021.

8. UNHCR. Global trends: forced displacement report 2018. 2018. https://www.unhcr.org/globaltren ds2018/. Accessed 10 Jan 2021. 
9. Conner P, Krogstad J. For the first time, U.S. resettles fewer refugees than the rest of the world. Pew Research Center. 2018. https://www.pewresearch.org/fact-tank/2018/07/05/for-the-first-time-us-resettles-fewer-refugees-than-the-rest-of-the-world/. Accessed 10 Jan 2021.

10. International Rescue Committee. Ten things to know about the global refugee crisis and America's lack of leadership. 2020. https://www.rescue.org/sites/default/files/document/3994/irc10thingstokn owabouttherefugeecrisisupdated2020-04.pdf. Accessed 10 Jan 2021.

11. Hoffmann R, Dimitrova A, Muttarak R, Cuaresma JC, Peisker J. A meta-analysis of country-level studies on environmental change and migration. Nat Clim Chang. 2020. https://doi.org/10.1038/ s41558-020-0898-6.

12. Bayar M, Aral M. An analysis of large-scale forced migration in Africa. Int J Environ Res Public Health. 2019. https://doi.org/10.3390/ijerph16214210.

13. Office of Refugee Resettlement. The Refugee Act. 2019. https://www.acf.hhs.gov/orr/policyguidance/refugee-act. Accessed 10 Jan 2021.

14. United States (US) Citizenship and Immigration Services. Refugee Screening Fact Sheet. 2020. https://www.uscis.gov/sites/default/files/document/fact-sheets/Refugee_Screening_and_Vetting_ Fact_Sheet.pdf. Accessed 10 Jan 2021.

15. Bruno A. FY2021 Refugee Ceiling and Allocations. Congressional Research Service. https:// crsreports.congress.gov/product/pdf/IN/IN11529. Accessed 8 June 2021.

16. UNHCR. International Organization for Migration and UNHCR announce temporary suspension of resettlement travel for refugees. 2020. https://www.unhcr.org/en-us/news/press/2020/3/5e710 3034/iom-unhcr-announce-temporary-suspension-resettlement-travel-refugees.html. Accessed 10 Jan 2021.

17. Shesgreen D, Subramanian C. Biden says he will raise refugee cap to 62,500 but warns the US will not be able to meet new number. USA Today. https://www.usatoday.com/story/news/polit ics/2021/05/03/joe-biden-lift-trump-era-refugee-cap-after-drawing-backlash/4929572001/. Accessed 10 Jan 2021.

18. Darrow J. The (Re)Construction of the U.S. Department of State's reception and placement program by refugee resettlement agencies. J Soc Soc Work Res. 2015. https://doi.org/10.1086/ 680341.

19. Office of Refugee Resettlement. Refugee Support Services. 2021. https:/www.acf.hhs.gov/orr/ programs/refugees/refugee-support-services. Accessed 10 Jan 2021.

20. Healthcare.gov. Coverage for lawfully present immigrants. 2021. https://www.healthcare.gov/ immigrants/lawfully-present-immigrants/. Accessed 10 Jan 2021.

21. Office of Refugee Resettlement. Refugees and the Affordable Care Act Fact Sheet. 2013. https:// www.acf.hhs.gov/sites/default/files/documents/orr/fact_sheet_refugees_and_the_affordable_ care_act_508_8_27_13b_508.pdf. Accessed 10 Jan 2021.

22. Kaiser Family Foundation. Health coverage of immigrants. 2020. https://www.kff.org/racialequity-and-health-policy/fact-sheet/health-coverage-of-immigrants/. Accessed 10 Jan 2021.

23. Palinkas LA, Pickwell SM, Brandstein K, Clark T, Hill L, Moser R, Osman A. The Journey to wellness: Stages of refugee health promotion and disease prevention. J Immigrant Health. 2003. https://doi.org/10.1023/A:1021048112073.

24. Marshall GN, Schell TL, Elliott MN, Berthold SM, Chun C. Mental health of Cambodian refugees 2 decades after resettlement in the United States. JAMA. 2005. https://doi.org/10.1001/ jama.294.5.571.

25. Nelson-Peterman JL, Toof R, Liang SL, Grigg-Saito DC. Long-term refugee health: Health behaviors and outcomes of Cambodian refugee and immigrant women. Health Educ Behav. 2015. https://doi.org/10.1177/1090198115590779.

26. Yun K, Hebrank K, Graber LK, Sullivan M, Chen I, Gupta J. High prevalence of chronic noncommunicable conditions among adult refugees: implications for practice and policy. J Community Health. 2012. https://doi.org/10.1007/s10900-012-9552-1.

27. Henkelmann JR, de Best S, Deckers C, Jensen K, Shahab M, Elzinga B, Molendijk M. Anxiety, depression and post-traumatic stress disorder in refugees resettling in high-income countries: systematic review and meta-analysis. BJPsych Open. 2020. https://doi.org/10.1192/bjo.2020.54.

28. Song S, Teichholtz S. Fact sheet: mental health facts on refugees, asylum-seekers, \& survivors of forced displacement. 2018. American Psychiatric Association Division of Diversity and Health Equity. https://www.psychiatry.org/psychiatrists/cultural-competency/education/mental-healthfacts. Accessed 10 Jan 2021. 
29. Hameed S, Sadiq A, Din AU. The increased vulnerability of refugee population to mental health disorders. Kansas J Med. 2018. https://doi.org/10.17161/kjm.v11i1.8680.

30. Steel Z, Silove D, Phan T, Bauman A. Long-term effect of psychological trauma on the mental health of Vietnamese refugees resettled in Australia: a population-based study. Lancet. 2002. https://doi.org/10.1016/S0140-6736(02)11142-1.

31. Miller KK, Brown CR, Shramko M, Svetaz MV. Applying trauma-informed practices to the care of refugee and immigrant youth: 10 clinical pearls. Children (Basel, Switzerland). 2019. https:// doi.org/10.3390/children6080094.

32. Li SS, Liddell BJ, Nickerson A. The relationship between post-migration stress and psychological disorders in refugees and asylum seekers. Curr Psychiatry Rep. 2016. https://doi.org/10.1007/ s11920-016-0723-0.

33. Caps R, Newland K. The integration outcomes of U.S. refugees. Migration Policy Institute. 2015. https://www.migrationpolicy.org/sites/default/files/publications/UsRefugeeOutcomes-FINALWEB. pdf. Accessed 10 Jan 2021.

34. Williams DR. Stress and the mental health of populations of color: advancing our understanding of race-related stressors. J Health Soc Behav. 2018. https://doi.org/10.1177/0022146518814251.

35. Vesely C, Bravo D, Guzzardo M. Immigrant families across the life course: policy impacts on physical and mental health. 2019. https://www.ncfr.org/sites/default/files/2019-07/Immigrant\%20Fam ilies\%20Executive\%20Summary_July\%202019.pdf. Accessed 10 Jan 2021.

36. Sarría-Santamera A, Hijas-Gómez AI, Carmona R, Gimeno-Feliú LA. A systematic review of the use of health services by immigrants and native populations. Public Health Rev. 2016. https://doi. org/10.1186/s40985-016-0042-3.

37. Siddiq H, Alemi Q, Mentes J, Pavlish C, Lee E. Preventive cancer screening among resettled refugee women from Muslim-majority countries: a systematic review. J Immigrant Minority Health. 2020. https://doi.org/10.1007/s10903-019-00967-6.

38. Shaw SA, Funk M. A Systematic review of social service programs serving refugees. Res Soc Work Pract. 2019. https://doi.org/10.1177/1049731518824405.

39. Yun K, Paul P, Subedi P, Kuikel L, Nguyen GT, Barg FK. Help-seeking behavior and health care navigation by Bhutanese refugees. J Community Health. 2016. https://doi.org/10.1007/ s10900-015-0126-X.

40. Refugee Council USA. Where are the refugees? 2019. https://rcusa.org/wp-content/uploads/2019/ 07/RCUSA-Report-1.pdf. Accessed 10 Jan 2021.

41. Saadi A, De Trinidad Young ME, Patler C, Estrada JL, Venters H. Understanding US immigration detention: Reaffirming rights and addressing social-structural determinants of health. Health Hum Rights. 2020;22:187-98.

42. American Civil Liberties Union. Timeline of the Muslim Ban. 2020. https://www.aclu-wa.org/ pages/timeline-muslim-ban. Accessed 10 Jan 2021.

43. Ku L. New evidence demonstrates that the Public Charge Rule will harm immigrant families and others. Health Affairs Blog. 2019. https://doi.org/10.1377/hblog20191008.70483.

44. Barofsky J, Vargas A, Rodriguez D, Barrows A. Spreading fear: the announcement of the public charge rule reduced enrollment in child safety-net programs. Health Aff (Millwood). 2020. https:// doi.org/10.1377/hlthaff.2020.00763.

45. American Civil Liberties Union (ACLU). Living with the Muslim Ban. 2020. https://www.aclu.org/ issues/immigrants-rights/living-muslim-ban. Accessed $10 \mathrm{Jan} 2021$.

46. American Academy of Family Physicians. Advancing health equity by addressing the social determinants of health in family medicine. 2019. https://www.aafp.org/about/policies/all/social-deter minants-health-family-medicine.html. Accessed 10 Jan 2021.

47. Metzl JM, Hansen H. Structural competency: theorizing a new medical engagement with stigma and inequality. Soc Sci Med. 2014. https://doi.org/10.1016/j.socscimed.2013.06.032.

48. Center for Substance Abuse Treatment (U.S.). Trauma-Informed Care in Behavioral Health Services. Rockville (MD): Substance Abuse and Mental Health Services Administration (US); 2014. (Treatment Improvement Protocol (TIP) Series, No. 57.) Chapter 2, Building a Trauma-Informed Workforce. https://www.ncbi.nlm.nih.gov/books/NBK207194/. Accessed 10 Jan 2021.

49. Ranjbar N, Erb M, Mohammad O, Moreno F. Trauma-informed care and cultural humility in the mental health care of people from minoritized communities. Focus. 2019. https://doi.org/10.1176/ appi.focus.20190027. 
50. Refugee Health. Best practices for communication through an interpreter. 2020. https://refugeehea lthta.org/access-to-care/language-access/best-practices-communicating-through-an-interpreter/. Accessed 10 Jan 2021.

51. Salami B, Salma J, Hegadoren K. Access and utilization of mental health services for immigrants and refugees: Perspectives of immigrant service providers. Int J Ment Health Nurs. 2018. https://doi. org/10.1111/inm.12512.

52. Clarke SK, Kumar GS, Sutton J, Atem J, Banerji A, Brindamour M, Geltman P, Zaaeed N. Potential impact of COVID-19 on recently resettled refugee populations in the United States and Canada: Perspectives of refugee healthcare providers. J Immigr Minor Health. 2020. https://doi.org/10.1007/ s10903-020-01104-4.

53. Saadi A, Rodriguez J. Addressing privacy concerns central to success of telehealth use among undocumented immigrants. Health Affairs Blog. 2020. https://doi.org/10.1377/hblog20201118. 621497.

54. Berlinger N, Zacharias R. Resources for teaching and learning about immigrant health in health profession education. AMA J Ethics. 2019;21(1):E50-57.

55. Keep Your Benefits. Understand how public benefits affect immigration options. 2020. https://www. keepyourbenefitsca.org/en/questionnaire. Accessed 10 Jan 2021.

56. Centers for Disease Control and Prevention. Refugee Health Profiles. 2020. https://www.cdc.gov/ immigrantrefugeehealth/profiles/index.html. Accessed 10 Jan 2021.

57. EthnoMed. Refugee Health Profiles. 2020. https://ethnomed.org/. Accessed 10 Jan 2021.

58. Society of Refugee Healthcare Providers. North American Refugee Health Conference. 2020. http:// refugeesociety.org/north-american-refugee-health-conference. Accessed 10 Jan 2021.

59. Saadi A. Welcoming and protecting immigrants in healthcare settings: A toolkit developed from a multi-state study. 2020. In: Doctors for Immigrants. https://doctorsforimmigrants.com/wp-content/ uploads/2020/01/WelcomingProtectingImmigrants-toolkit-3.pdf. Accessed 5 May 2021.

Publisher's Note Springer Nature remains neutral with regard to jurisdictional claims in published maps and institutional affiliations.

Hafifa Siddiq is a doctorate-prepared registered nurse and a postdoctoral fellow at the National Clinician Scholars Program at UCLA. Her research examines preventive health and mental health service use among resettled refugees and asylum seekers in the USA. Dr. Siddiq is currently involved in communitypartnered research funded through the UCLA RCMAR/CHIME examining pathways to counseling and community mental health services among older refugees.

Julia Rosenberg is a graduate of the Yale Pediatrics Residency program and postdoctoral fellow at the National Clinician Scholars Program at Yale University. Dr. Rosenberg received her undergraduate degree from Cornell University and graduated from Weill Cornell Medical College. Throughout her medical education, she has been involved in global health initiatives as well as in immigrant and refugee healthcare. Her research examines immigrant and refugee health, access to healthcare for patients with low English proficiency, and the medical-legal issues affecting these populations. 